\title{
Adjuvant Endocrine Therapy in Breast Cancer: A Novel e-Health Approach in Optimizing Treatment for Seniors (OPTIMUM): A Two-Group Controlled Comparison Pilot Study
}

Ari Meguerditchian ${ }^{1,2,3,4}$, MSc, MD; Robyn Tamblyn ${ }^{1,5,6}, \mathrm{PhD}$; Sarkis Meterissian ${ }^{2,3,4}$, MSc, MD; Susan Law ${ }^{7,8}, \mathrm{PhD}$; Jaroslav Prchal ${ }^{3,9}$, MD; Nancy Winslade ${ }^{6}$, MHPE, PharmD; Donna Stern ${ }^{9}$, MD

${ }^{1}$ Clinical and Health Informatics Research Group, McGill University, Montreal, QC, Canada

${ }^{2}$ Department of Surgery, McGill University, Montreal, QC, Canada

${ }^{3}$ Department of Oncology, McGill University, Montreal, QC, Canada

${ }^{4}$ Breast Clinic, McGill University Health Centre, Montreal, QC, Canada

${ }^{5}$ Department of Epidemiology, Biostatistics and Occupational Health, McGill University, Montreal, QC, Canada

${ }^{6}$ Department of Medicine, McGill University, Montreal, QC, Canada

${ }^{7}$ Department of Family Medicine, McGill University, Montreal, QC, Canada

${ }^{8}$ Research Centre, St. Mary's Hospital, Montreal, QC, Canada

${ }^{9}$ Department of Oncology, St. Mary's Hospital Center, Montreal, QC, Canada

\section{Corresponding Author:}

Ari Meguerditchian, MSc, MD

Clinical and Health Informatics Research Group

McGill University

1140 Pine Avenue West

Montreal, QC

Canada

Phone: 15149341934 ext 32999

Fax: 15148431633

Email: ari.meguerditchian@mcgill.ca

\section{Abstract}

Background: In women with hormone receptor positive breast cancer, adjuvant endocrine therapy (AET) is associated with a significant survival advantage. Nonadherence is a particular challenge in older women, even though they stand to benefit the most from AET. Therefore, a novel eHealth tool (OPTIMUM) that integrates real-time analysis of health administrative claims data was developed to provide point-of-care decision support for clinicians.

Objectives: The objectives of the study are to determine the effectiveness of a patient-specific, real-time eHealth alert delivered at point-of-care in reducing rates of AET discontinuation and to understand patient-level factors related to AET discontinuation as well as to assess integration of eHealth alerts regarding deviations from best practices in administration of AET by cancer care teams.

Methods: A prospective, 2-group controlled comparison pilot study will be conducted at 2 urban, McGill University-affiliated hospitals, the Royal Victoria Hospital and St. Mary's Hospital. A minimum of 43 patients per study arm will be enrolled through site-level allocation. Follow-up is 1.5 years. Health care professionals at the intervention site will have access to the eHealth tool, which will report to them in real-time medical events with known associations to AET discontinuation, an AET adherence monitor, and a discontinuation alert. Cox proportional hazard ratios with $95 \%$ confidence intervals will estimate risks of AET discontinuation. Tests for significance will be 2 -sided with a significance level of $P<.05$.

Results: This protocol has been approved and funded by the Canadian Institutes of Health Research. The study will evaluate site-level differences between AET discontinuation and AET adherence and assess care team actions at the intervention site. Participant enrollment into this project is expected to start September 2016 with primary data ready to present by June 2018.

Conclusion: This study will offer an opportunity to verify the feasibility of integrating an eHealth tool that aims to improve the long-term management of breast cancer in a high-risk population by allowing more timely intervention to prevent or rapidly address AET discontinuation. 
(JMIR Res Protoc 2016;5(4):e199) doi: 10.2196/resprot.6519

\section{KEYWORDS}

administrative claims; health care; breast neoplasms; medical informatics applications; aromatase inhibitors; telemedicine; health services for the aged; medication adherence

\section{Introduction}

\section{Antiestrogen Therapy in Seniors With Breast Cancer: An Effective Anticancer Strategy}

Adjuvant endocrine therapy (AET) inhibits the estrogenic stimulation that drives breast cancer growth [1-4]. In women with hormone receptor positive breast cancer, AET is associated with a significant survival advantage [2,5-8]. For instance, tamoxifen reduces the relative risk of recurrence and death from breast cancer by $46 \%$ and $26 \%$, respectively [6], with maximal benefits attained from at least 5 years of therapy [9-13]. Similar outcomes are reported with aromatase inhibitors [10,14-17]. Therefore, when taken for at least 5 years, AET is a low-risk, easily administered treatment that constitutes an ideal strategy in reducing the impact of disease in women with hormone receptor positive breast cancer.

Defined as the extent to which patients take a medication as prescribed [18-22], adherence is the most important modifiable factor that can potentially compromise treatment outcome [23,24]. Adherence problems lead to worsening of disease, increased hospitalizations and health care costs, and death [25-31]. Suboptimal adherence can be due to factors related to patient, provider, and health care system characteristics [18,21]. Despite the magnitude of breast cancer as a health problem and the impressive survival benefits of AET, nonadherence rates of more than $20 \%$ have been noted in tightly controlled clinical trials [32-34]. However this does not accurately reflect the reality of vulnerable patients such as older women, who tend to be underrepresented in research studies [35-38].

Limited studies show that adherence to AET is a particular challenge in older women [39]. Paradoxically, these women stand to benefit the most from AET, because breast cancer is hormone receptor positive in more than $80 \%$ of women 65 years and older [40-46], older patients are often precluded from other more toxic forms of systemic treatment such as chemotherapy [47], and the use of AET simplifies managing breast cancer in seniors by eliminating the need for other forms of treatment. For example, radiotherapy can be omitted in patients 70 years and older after breast conserving surgery for stage I disease, providing they receive AET [48,49]. Specifically, in patients older than 65 years old, AET has been shown to improve 15 -year survival by at least $21 \%$ [50]. Consequently, the International Society of Geriatric Oncology recommends that seniors with hormone receptor positive breast tumors benefit from AET, because there is no evidence of age-related differences in the efficacy of tamoxifen and aromatase inhibitors [50,51].

Because close to $40 \%$ of breast cancers in Canada are diagnosed in women 65 years and older and $61 \%$ of deaths from this disease occur in women 70 years and older [52], it is crucial that we gain a better understanding of problems associated with AET adherence in this population.

\section{Adherence to Adjuvant Endocrine Therapy: Tackling Challenges in Older Women}

Conventional strategies in documenting adherence to AET (eg, chart review, patient self-report, metabolite measurement, pill counts) are limited by their reliability and applicability [53-57]. They do not correspond well to the reality of taking AET, a self-administered daily treatment that requires minimal interaction with the care team, for seniors who often have other comorbidities (and thus additional prescriptions). As a result, opportunities to identify problems throughout the course of treatment and intervene are limited [58,59].

Generated for the purpose of directing payment, administrative claims constitute a source of potentially complete health care information covering all services provided to a patient, including outpatient drugs [60]. We have previously demonstrated that pharmacy claims were superior to a national cancer registry in reporting delivery of outpatient self-administered treatments. Initiation of AET was documented in an additional 55\% of patients in comparison to registry data from the National Cancer Data Base [61].

Online adjudication processes of drug insurance programs and electronic storage of claims data ensure both timeliness and longitudinal compilation of information on drug utilization. This can be used to assess adherence to AET by seniors by calculating the medication possession ratio (MPR) based on refill rates, which reflect the availability of medication supply [62]. Defined as the ratio of total days covered by medication divided by the number of days needing the medication [21,63], the MPR estimates the proportion of days on which medication is taken and appears to be a better predictor of therapeutic outcomes compared to self-report or pill count [64-66].

Using pharmacy claims from all Quebec breast cancer patients (1998-2007), we have shown that adherence to AET among older women is suboptimal across each of the 5 years of treatment, falling below $75 \%$ at the fifth year $[67,68]$. We have shown that $37 \%$ of patients experience discontinuation of some duration within the first year [67]. Using health service claims, we have further demonstrated that hospitalizations, addition of new drugs during therapy, switch in AET type (tamoxifen versus aromatase inhibitor), and depression are associated with higher rates of nonpersistence.

To date, very few studies have used pharmacy claims to characterize AET adherence in seniors with breast cancer. Using the cohort of Quebec women aged 70 years and older (1998-2005), our group has demonstrated that $32 \%$ of older patients discontinued AET at some point during therapy and $20 \%$ of these women permanently abandoned therapy, thus losing the significant age-specific survival advantage provided by this treatment $[50,69,70]$. We have also shown that treatment discontinuation was more frequent in seniors who had 
encountered irregularities and gaps in quality in other aspects of breast cancer care.

\section{Medical Office of the XXIst Century: A Novel eHealth Tool to Optimize Breast Cancer Care Delivery in Seniors}

Medical Office of the XXIst Century (MOXXI) is a novel clinical informatics system that provides patient-specific, point-of-care documentation and decision support through real-time processing of health services claims [71-73]. This platform also allows analysis of treatment plan variations. The disease-specific, real-time, point-of-care informatics support provided by MOXXI has been associated with better, safer care. For example, in the case of cardiovascular medications, physicians who received automated alerts from MOXXI regarding low treatment adherence (based on a real-time feed from the provincial pharmacy claims database) were significantly more likely to review the patient's drug profile and take appropriate action [73]. Another MOXXI application directed at older adults provides real-time alerts to physicians regarding the risk of fall-related injury in relation to the patient's psychoactive medications. This eHealth tool has been shown to result in treatment plan modifications in $24.6 \%$ of patients and a reduction of injury risk by 1.7 injuries per 1000 patients $[74,75]$.

The integration of eHealth tools such as MOXXI represents a unique opportunity to address challenges in the delivery of care for older women diagnosed with breast cancer [76]. With multiple medical comorbidities, extensive health service use, and frequent deviations from best practices for cancer treatment, this group stands to benefit the most from the development of a comprehensive cancer care quality strategy addressing all components of treatment, continuously integrating all aspects of their health, and supporting treatment decisions specific to their needs [77,78].

\section{Purpose and Objectives}

The aim of this study is to verify if a patient-specific eHealth tool (OPTIMUM) that integrates real-time analysis of administrative claims data and provides point-of-care risk assessment to care teams will optimize breast cancer treatment by increasing adherence and persistence to antiestrogen therapy in patients aged 65 years and older.

The first objective is to determine the effectiveness of OPTIMUM's patient-specific, real-time eHealth alerts in reducing rates of AET discontinuation in older women with breast cancer and understand patient-level factors related to AET discontinuation.

The second objective is to assess integration of the eHealth alerts reporting deviations from best practices in administration of AET by evaluating cancer care team responses.

\section{Methods}

\section{Overview}

A prospective, 2-group controlled comparison pilot study will be conducted to test the hypothesized benefits of the OPTIMUM eHealth tool with integrated alerts in managing AET in seniors with breast cancer (see Figure 1 for study flow). The benefits of the intervention will be assessed by comparing patients of care teams using the OPTIMUM eHealth tool with patients of care teams contemporaneously provided usual care. The follow-up will last 1.5 years based on previous findings by our group that the median time to first AET discontinuation in 3180 Quebec women (aged 70 years and older) with early stage breast cancer was 1.5 (range 0.5-3.4) years [69]. Ethics approval will be obtained before initiating the study. 
Figure 1. Flowchart of study design: a prospective intervention study with a contemporaneous control group.

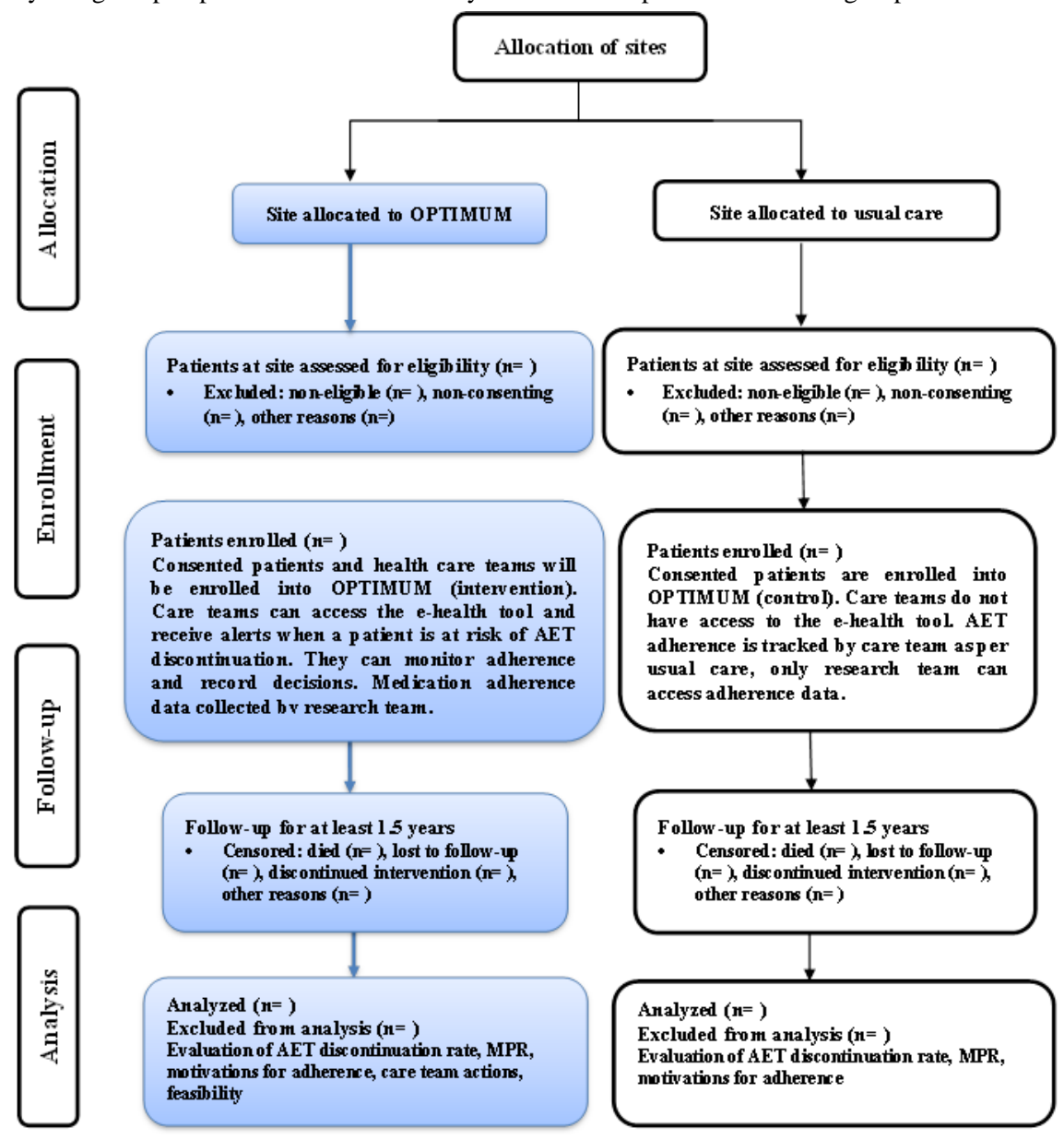

\section{Study Population and Setting}

The study will take place at 2 urban hospitals in Montreal, Canada: the Royal Victoria Hospital (RVH) and St. Mary's Hospital (SMH). These hospitals were selected for comparable resources and treatment standards. Both hospitals are affiliated with McGill University and benefit from its clinical trials infrastructure. In addition, both sites have similar multidisciplinary care teams consisting of surgical, medical, and radiation oncologists and an oncology nurse specialist. Staff and support resources are allocated at the institution level, where patient management is standardized. A total of 1168 new breast cancer patients were treated at both sites in 2012 with about $40 \%$ of the women being over the age of 65 years [79].

\section{Eligibility Criteria}

Eligible patients from the 2 study sites will be identified by the oncology nurse specialist. To be eligible to participate in this study, patients must be 65 years or older, able to give consent, and diagnosed with incident (nonmetastatic) breast cancer after having undergone breast surgery for stages I-III disease. Patients must have had medical insurance with the Régie de l'Assurance Maladie du Québec (RAMQ) for at least 1 year prior to surgery and have histologically confirmed breast adenocarcinoma with hormone receptor positive disease. Patients must have no history of AET use prior to the diagnosis of breast cancer, expect to initiate AET or have only recently initiated AET (less than 6 months), and be free of previous discontinuation events.

\section{Recruitment}

Patients will be recruited exclusively from the breast centers participating in the study (RVH and SMH). Advertisements will be placed in the registration areas, waiting rooms, and clinical care areas. Care teams (physicians, oncology nurses, and rehabilitation specialists) will facilitate identification of eligible patients and secure their permission to be approached by a study coordinator who will inform patients about the study and provide a detailing pamphlet. Only patients and health care professionals who have provided a standardized consent form with their signatures will be enrolled in the study. Both patients and care teams will be aware that the intervention site will receive the eHealth tool to test the study hypothesis. However, only the health care professionals will know if their site has the intervention based on their site's receipt of the eHealth tool. This intervention is not expected to impact the care of patients at the control site because AET adherence optimization is part of best practices. For additional validation, adherence of participants at the control site can be compared to historical population-based adherence data $[67,68]$.

\section{Intervention Allocation}

All eligible patients who provide consent will be enrolled into OPTIMUM. The intervention allocation will occur at the site level. The care team at RVH will have access to the OPTIMUM eHealth tool (intervention). At SMH, the care team will continue to deliver care according to standard processes (control group). 
The control and intervention sites were selected for their similarities in source population, breast cancer volume, practice profiles, and academic affiliation. In addition, both institutions recently underwent administrative and physical reorganizations of the same magnitude. RVH completed their transition several months earlier than $\mathrm{SMH}$, which enabled the process of logistical implementations related to the intervention and ethics approval for this pilot to start earlier there.

\section{Intervention: An eHealth Tool}

The intervention site care team will receive the following 3 OPTIMUM eHealth alerts (for care team process flow, see Figure 2).

Figure 2. Process flow for care teams.
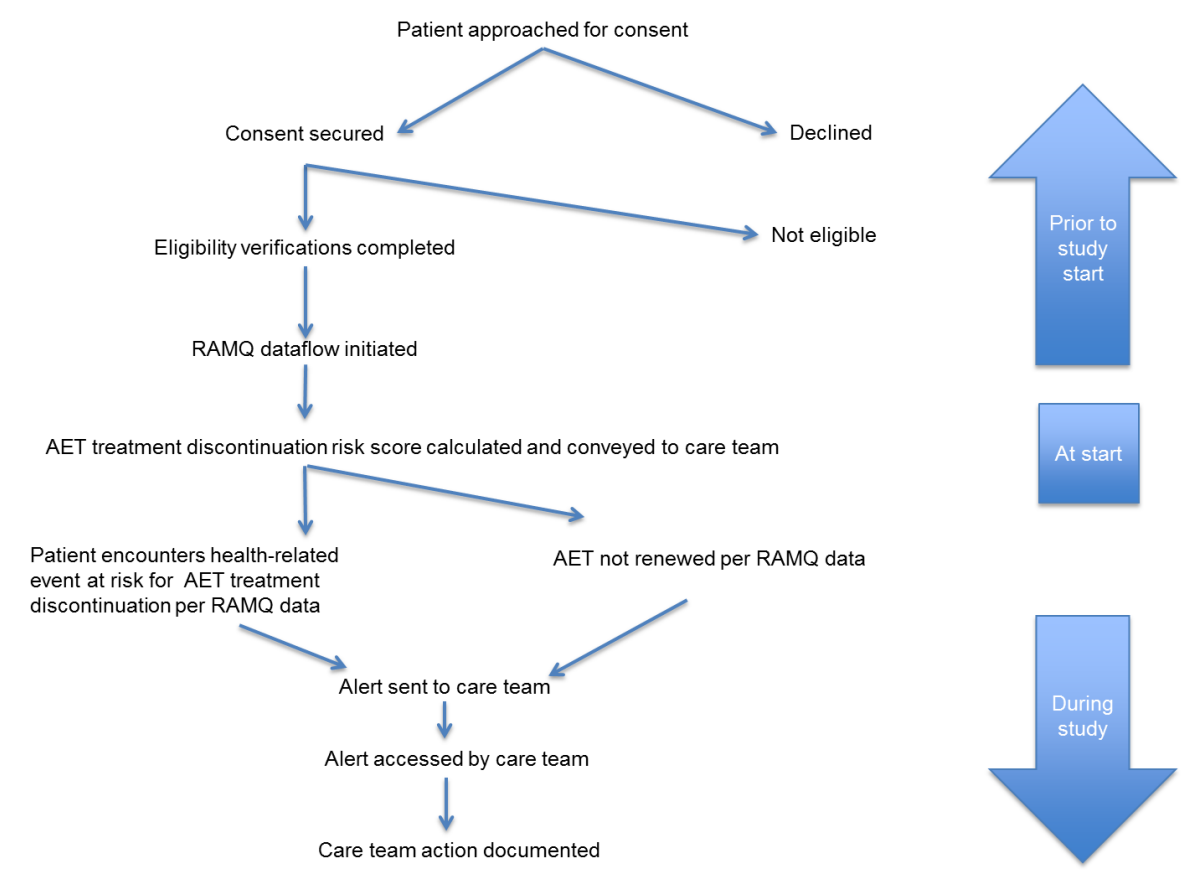

\section{Electronic Alert of Increased Adjuvant Endocrine Therapy Discontinuation Risk}

Through real-time analysis of health service claims, OPTIMUM will generate this alert when a hospitalization, emergency room visit, addition of new medications, or change in AET drug occurs (see Multimedia Appendix 1-2 for examples of alerts from another eHealth tool trial). We have previously demonstrated that the occurrence of these during AET negatively impacts treatment adherence. The care team will be prompted by the eHealth tool to log its actions upon receipt of these alerts. The choice of actions is at the discretion of the care team and may include performing telephone follow-up with patient, performing telephone follow-up with community pharmacist, arranging for return to clinic with doctor, arranging for return to clinic with nurse, or ignoring the alert (see Multimedia Appendix 1-3 for examples of another eHealth tool and Multimedia Appendix 4 for the types of actions the care teams can select when faced with an alert).

\section{Adherence Monitor}

As the treatment progresses, OPTIMUM will provide a graphic representation of adherence to AET over time for each patient (see Multimedia Appendix 3 for example).

\section{Electronic Discontinuation Occurrence Alert}

Through real-time analysis of pharmacy claims including information on renewal date and number of pills dispensed, OPTIMUM will generate an electronic alert when there is a gap in AET prescription renewal within 10 days of the expected date. This threshold was determined from secondary analysis of our previous publications $[67,68]$, which found that most patients who did not discontinue permanently renewed AET within 10 days. Again, the care team will be prompted by the eHealth tool to log its actions upon receipt of these alerts. The choice of actions are at the discretion of the care team and may include performing telephone follow-up with patient, performing telephone follow-up with community pharmacist, arranging for return to clinic with doctor, arranging for return to clinic with nurse, or ignoring the alert (see Multimedia Appendix 1-3 for examples of another eHealth tool and Multimedia Appendix 4 for the types of actions the care teams can select when faced with an alert).

\section{Control Site}

Care teams at the hospital assigned as control site will follow up with patients according to standard processes of care and will not have access to the eHealth tool.

\section{Sample Size}

A minimum of 120 patients will be approached to obtain a pilot sample size of 43 patients per arm [80,81]. This assumes comparable care standards between arms and among clinicians, an enrollment rate of $75 \%$, a $5 \%$ loss to follow-up for infrequent cases of patient migration or opting out of the government drug plan [68], with a proportion of $20 \%$ permanently discontinuing at the control site $[67,68]$ and $14 \%$ in the intervention group (minimally clinical important risk difference of $6 \%$, a relative effect of $30 \%$ ). 


\section{Data Sources}

The following data sources will be linked to obtain important patient, disease, and clinical information and verify study outcomes (see Textbox 1).

Registrant database of insured persons documents year of birth, gender, 3-digit postal code, and date of death for all Quebec residents eligible for provincial health insurance coverage (approximately 99\% of the population of Quebec), as well as dates for any noninsured periods $[82,83]$.

RAMQ medical service claims database (RAMQ-MD) contains records for all services provided within Quebec's public health insurance plan by physicians remunerated under the fee-for-service system (approximately 96\% of physicians in Quebec). This database includes encrypted physician license number, physician speciality, service date, code for the service provided, location of service delivery (eg, community health services center, hospital) and primary diagnosis codes (International Classification of Diseases, Ninth Revision [ICD-9]). Previous studies have demonstrated that diagnostic codes in medical service claims have high specificity, high positive predictive value, and high negative predictive value, estimated at above $90 \%$ for all 3 indicators [84].
RAMQ drug insurance eligibility database contains start and end dates of patient eligibility for public drug insurance as well as the type of drug plan.

RAMQ prescription claims database (RAMQ-Rx) contains claims for prescription drugs dispensed to all Quebec residents insured under the public drug plan. It includes encrypted physician license number, Drug Identification Number of drug dispensed, date the medication was dispensed, quantity dispensed, and duration of the prescription. Our group has shown that the accuracy of this database in identifying the correct drug dispensed is over $99 \%$ [85].

MedEcho is the hospital's discharge database, which includes admission date, principal and secondary diagnoses, and services performed for all discharges from acute care hospitals in the province. The first hospital-based service for breast cancer is considered the patient's index date.

Hospital chart includes all clinical notes of treatment decisions and clinical course.

The RAMQ links the above data sources using the numéro d'assurance-maladie, a unique identifier attributed to each Quebec resident and common to these databases. Appropriate clearance has been obtained from the Commission d'accès à l'information $d u$ Québec for the use of these population databases.

Textbox 1. Data sources and look-back periods with type of information extracted.

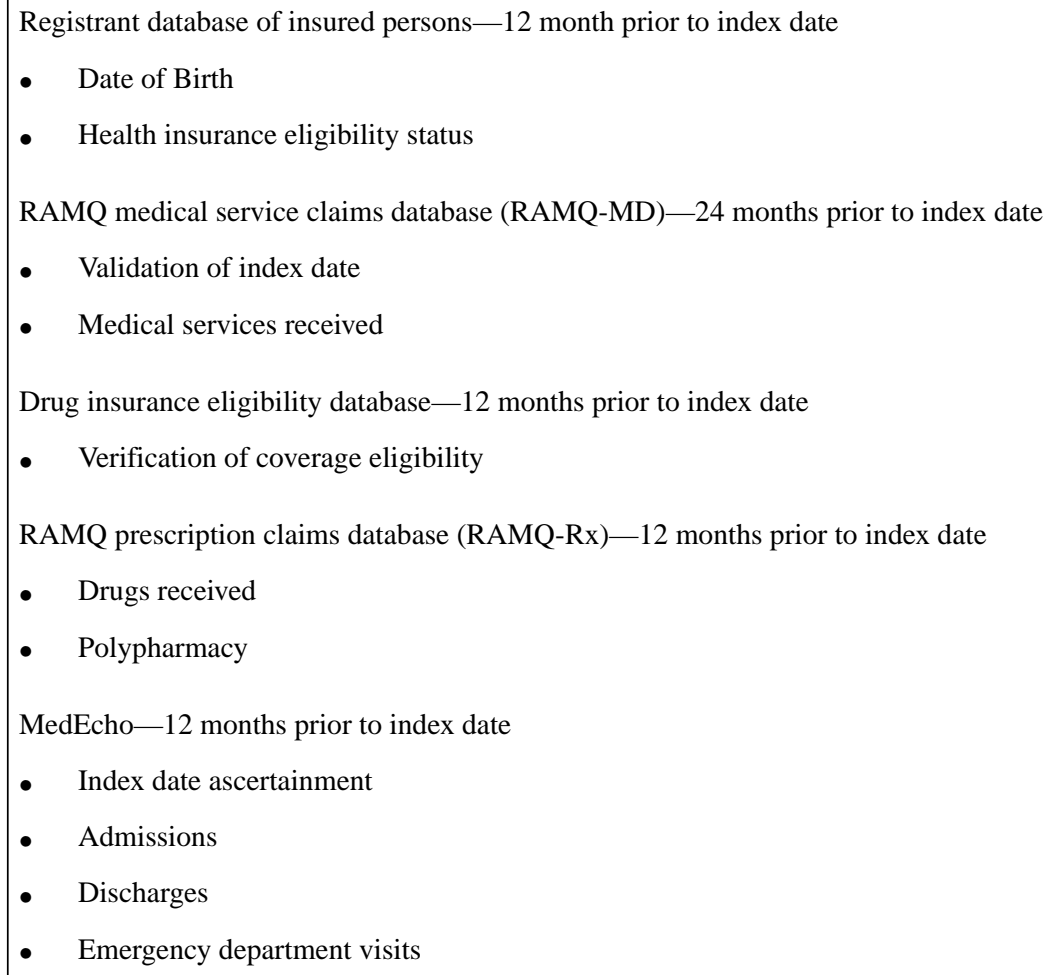

\section{Confounding Variables}

\section{Patient Demographics (Fixed Covariates)}

Age at diagnosis will be obtained from the registrant database. Socioeconomic status information will be obtained using the RAMQ-Rx database. A variable will be created grouping patients according to income supplementation received by the government. Patients will either "not qualify for a supplement," "qualify for some supplement," or "qualify for maximum supplement." 


\section{Disease Characteristics (Fixed Covariate)}

We will identify the patient's breast cancer stage using topography and morphology (ICD-9) codes recorded in the hospital's discharge database (MedEcho).

\section{Treatment Characteristics (Fixed Covariates)}

We will characterize delivery and date for each component of breast cancer care (itemized below) using medical services billing codes in the RAMQ-MD and prescription drug claims in the RAMQ-Rx databases. As previously discussed, claims offer the opportunity to accurately monitor breast cancer patient progress through the cancer care continuum because they cover all services provided regardless of practitioner or site.

- Breast surgery: mastectomy, lumpectomy, no surgery

- Axillary surgery: sentinel lymph node biopsy, axillary lymph node dissection, no lymph node surgery

- Radiation therapy: consultation with radiation oncology, delivery of external beam radiation therapy, no radiation therapy

Systemic therapy: consultation with medical oncology, delivery of systemic chemotherapy, no chemotherapy

AET initiation: 3 variables will be created-choice of drug (tamoxifen, anastrosole, letrosole or exemestane), timeliness of treatment initation (1 year or less), and whether the patient switched type of AET during follow-up

\section{Other Medical Conditions (Fixed Covariates)}

Romano's adaptation of the Charlson comorbidity index will be used to measure each patient's baseline risk of discontinuing in relationship to their health status using ICD-9 codes listed in claims in the 12 months prior to the diagnosis of breast cancer. In addition, the MedEcho database will be used to document the number of emergency department visits and inpatient admissions for each 12-month period following AET start.

\section{Polypharmacy (Fixed Covariates)}

Drug claims for the 12 months preceding AET start, supplied by the RAMQ-Rx, will be classified according to the American Hospital Formulary Classification to determine the baseline number of different categories of non-AET drugs prescribed at the start of the AET treatment.

\section{Physician Characteristics (Fixed Covariates)}

Prescribing physician specialty, supplied by the RAMQ-Rx, may influence a patient's adherence to treatment. Therefore, the specialty of the first physician to prescribe AET to the patient will be identified. We will calculate the number of women with a breast cancer diagnosis that this first prescribing physician billed a medical service claim for in the year prior to initiating the patient's treatment. In addition, the physician's experience in treating breast cancer patients will be obtained. Finally, the number of different physicians who prescribed the patient's AET will be recorded. No information that can potentially identify physicians will be collected.

\section{Definitions of Outcomes}

The primary outcome is an AET discontinuation event defined as failure to refill an AET prescription within 10 days after the due refill date. The first due refill day preceding a gap of 10 days would be considered the date of discontinuation event. Permanent AET discontinuation will be defined as failure to refill an AET prescription before the end of the first year of treatment. First-year adherence will be measured by the MPR, defined as the proportion of days covered by medication supply in the treatment period. Actions taken by care teams upon receipt of an alert from the OPTIMUM eHealth tool will be observed and logged with the purpose of developing future AET adherence intervention strategies. These actions could be part of a drop-down menu and may include: perform telephone follow-up with patient, perform telephone follow-up with community pharmacist, arrange for return to clinic with doctor, arrange for return to clinic with nurse, or ignore the alert.

\section{Operationalization of Outcomes}

Visual representation of outcomes to be quantified during the course of the study and according to the study arm is shown in Figure 3.

AET discontinuation will be assessed by determining the proportion of patients permanently discontinuing AET treatment, proportion of patients reinitiating after a discontinuation of AET treatment, and the mean time to AET treatment reinitiation. This will be calculated in both the intervention and control arms. These outcomes will then be compared between both arms at the end of the study by the research team.

The MPR will be assessed as the mean MPR, and the proportion of patients that maintain an MPR of $80 \%$ or more. This will calculated in both intervention and control arms. Outcomes will be compared between both arms at the end of the study by the research team.

Types of actions taken by health care teams upon alert receipt will be assessed qualitatively and quantitatively in the intervention arm. As detailed above, the eHealth tool users will be prompted to document actions in response to an alert through a drop-down function in OPTIMUM. These actions will be logged in real-time when a notification is accessed and recorded. The outcome will be tabulated at the end of the study by the research team. 
Figure 3. Outcomes by study arm.

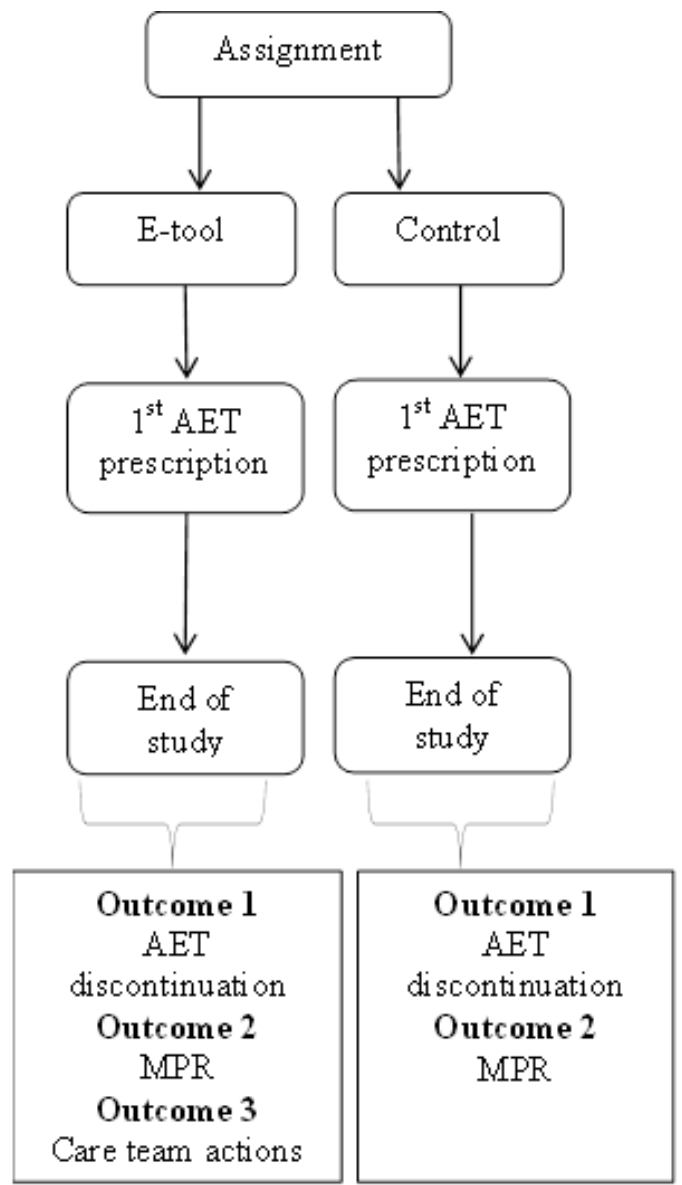

\section{Statistical Analysis}

\section{Assessing Effectiveness of the OPTIMUM eHealth Tool at Reducing Adjuvant Endocrine Therapy Rates of Discontinuation}

In order to assess if the OPTIMUM eHealth tool has an impact on adherence, rates of AET discontinuation and MPR will be evaluated and compared between the intervention and control groups at the end of the follow-up period. Univariate and multivariate Cox proportional hazards regression models will be used to analyze the association between rates of AET discontinuation in patients managed with the OPTIMUM eHealth tool versus those in usual care, while adjusting for known patient clinical and demographic factors. These factors include age, hospitalizations, type of AET, depression, Charlson Comorbidity Index, and polypharmacy at baseline [69].

Time to treatment discontinuation will be measured using Kaplan-Meier analysis. The MPR will be calculated at the end of the study period. Patients will be classified as adherent if they maintain an MPR of $80 \%$ or more. Univariate and multivariate logistic regression analysis will be used to assess the association between the OPTIMUM eHealth tool and maintaining an MPR of $80 \%$ of more while adjusting for known risk factors. The proportion of patients discontinuing in each group (intervention vs usual care) and restarting medication will be compared using a chi-square test. The mean time to restart will be compared using a $t$ test in those who restart after a treatment discontinuation event.

\section{Assessing Integration of eHealth Alerts Concerning Deviations From Best Practices}

Actions taken by health care teams in response to alerts (intervention arm) will be documented and assessed both qualitatively and via descriptive statistics. Descriptive statistics will be used to evaluate the most common action performed upon receiving an alert, frequency of log-ins to visit the patient's profile, frequency of viewing the adherence monitor, frequency and types of actions selected from the drop-down menu, or other actions such as change in treatment plan.

\section{Confidentiality}

\section{Identity Protection}

In order to protect confidentiality for study participants, all identifying information will be removed from the files prior to analysis. Therefore, research data transactions will be performed on deidentified data only using a unique study number assigned to each subject (includes patients and physicians). Only this number will be used on research documents that relate to the subject. Team members will be required to sign a confidentiality agreement with the principal investigator prior to accessing the information. The linkage table of subject names and corresponding study numbers will be kept in a secure locked location accessible only to the principal investigator (or his delegate). No names will be released and only grouped data will be presented in oral or written scientific communications. Identifying information will be destroyed 5 years after publication of findings. 


\section{Data Storage}

Collected research data will be saved on research servers independent from and outside of the 2 clinical care sites. These servers are located at McGill University's data center, and access to them is protected by alarm system and 24-hour guard surveillance. In addition, informatics data transactions through these servers occur in the context of a private network and require username and password. Transactions are recorded and trackable by our in-house information technology networks specialist. Access to the server is restricted; it has the latest and most sophisticated protection against unauthorized intrusions and potential damage. This type of design offers a high level of data security in the event that a computer is lost or stolen.

\section{Ethical Considerations}

The OPTIMUM study will be conducted according to ethical principles stated in the Declaration of Helsinki (2013). This study received ethics approval from McGill University Health Centre Research Ethics Board on August 16, 2016. Consent forms will take into consideration the well-being, free-will, and respect of the participants (including respect of their privacy).

\section{Results}

Participant enrollment into this project is expected to start in September 2016 with primary data ready to present by June 2018.

\section{Discussion}

Over $40 \%$ of breast cancers in Canada occur in women 65 years and older. AET is an effective approach in reducing recurrence and cancer death in these women. Unfortunately, adherence to AET in this population is suboptimal.

This study aims to use a 2-group controlled comparison pilot study to verify the feasibility of integrating eHealth tools that aim to improve the management of the breast cancer in this high-risk population by allowing more timely intervention to prevent or rapidly address treatment discontinuation. Our group has already developed a successful model of using information technology to provide real-time decision support and feedback to care teams on patient-specific risk profiles. With the knowledge generated from this research, we plan to develop an informatics tool that would provide health professionals with a new generation of decision-support tools specific to the older cancer patients' needs. As this study is a pilot, feedback from care teams on ease of integrating the eHealth tool into existing workflows will support and guide the launch of a larger scale longitudinal study.

Our multidisciplinary team of scientists brings together research expertise from medicine, surgery, nursing, pharmacy, psychology, and evaluative sciences in developing the next generation of informatics-enabled tools in optimizing breast cancer care. Research will take place at the Clinical and Health Informatics Research Group. The Group is experienced in handling electronic clinical data systems such as hospital clinical data warehouses, RAMQ administrative databases, and clinical competency data through the Medical Council of Canada/College of Physicians of Quebec. Over the past decade, it has developed extensive know-how in developing value-added health informatics tools to improve health outcomes.

\section{Acknowledgments}

This protocol has been approved and funded by the Canadian Institutes of Health Research.

\section{Conflicts of Interest}

None declared.

\section{Multimedia Appendix 1}

Visual depiction of the type of patient-specific alerts that can be provided to the health care professional borrowed from another trial on the effectiveness of MOXXI in improving care quality. This is an example of a patient-specific, real-time MOXXI alert provided to the care team regarding a prescription duplication and specific drug-related risk.

\section{[PNG File, 194KB-Multimedia Appendix 1]}

\section{Multimedia Appendix 2}

Visual depiction of the type of patient-specific alerts that can be provided to the health care professional borrowed from another trial on the effectiveness of MOXXI in improving care quality. This is a notification of events associated with an increased risk of drug-related issue (ie, emergency department visits).

[PNG File, 522KB-Multimedia Appendix 2]

\section{Multimedia Appendix 3}

Visual depiction of the type of patient-specific alerts that can be provided to the health care professional borrowed from another trial on the effectiveness of MOXXI in improving care quality. This is a graphical representation of drug adherence over time. 


\section{Multimedia Appendix 4}

Example of how MOXXI, an eHealth tool, can be used to document an action and its rationale upon receipt of a patient-specific alert. In this example, the action is to stop a drug, and the drop-down list follows with reasons for changing the prescription.

[PNG File, 120KB-Multimedia Appendix 4]

\section{Multimedia Appendix 6}

Protocol approval and review by the Canadian Institutes of Health Research.

[PDF File (Adobe PDF File), 293KB-Multimedia Appendix 6]

\section{References}

1. Clemons M, Goss P. Estrogen and the risk of breast cancer. N Engl J Med 2001 Jan 25;344(4):276-285. [doi: 10.1056/NEJM200101253440407] [Medline: 11172156]

2. Brueggemeier RW, Hackett JC, Diaz-Cruz ES. Aromatase inhibitors in the treatment of breast cancer. Endocr Rev 2005 May;26(3):331-345. [doi: 10.1210/er.2004-0015] [Medline: 15814851]

3. Jänicke F. The similarities of aromatase inhibitors outweigh the differences. Anticancer Drugs 2008 Mar;19 Suppl 2:S7-S9. [doi: 10.1097/01.cad.0000277874.73498.56] [Medline: 18337642]

4. Osborne CK. Tamoxifen in the treatment of breast cancer. N Engl J Med 1998 Nov 26;339(22):1609-1618. [doi: 10.1056/NEJM199811263392207] [Medline: 9828250]

5. Harichand-Herdt S, Zelnak A, O'Regan R. Endocrine therapy for the treatment of postmenopausal women with breast cancer. Expert Rev Anticancer Ther 2009 Feb;9(2):187-198. [doi: 10.1586/14737140.9.2.187] [Medline: 19192957]

6. Early Breast Cancer Trialists' Collaborative Group. Effects of chemotherapy and hormonal therapy for early breast cancer on recurrence and 15-year survival: an overview of the randomised trials. Lancet 2005;365(9472):1687-1717. [doi: 10.1016/S0140-6736(05)66544-0] [Medline: 15894097]

7. Visvanathan K, Hurley P, Bantug E, Brown P, Col NF, Cuzick J, et al. Use of pharmacologic interventions for breast cancer risk reduction: American Society of Clinical Oncology clinical practice guideline. J Clin Oncol 2013 Aug 10;31(23):2942-2962. [doi: 10.1200/JCO.2013.49.3122] [Medline: 23835710]

8. National Comprehensive Care Network. NCCN clinical practice guidelines in oncology. URL: https://www.nccn.org/ professionals/physician gls/f guidelines.asp [accessed 2016-10-04] [WebCite Cache ID 610xJ6Xov]

9. Swedish Breast Cancer Cooperative Group. Randomized trial of two versus five years of adjuvant tamoxifen for postmenopausal early stage breast cancer.. J Natl Cancer Inst 1996 Nov 6;88(21):1543-1549 [FREE Full text] [Medline: $\underline{8901852]}$

10. Markopoulos CJ. Minimizing early relapse and maximizing treatment outcomes in hormone-sensitive postmenopausal breast cancer: efficacy review of AI trials. Cancer Metastasis Rev 2010 Dec;29(4):581-594 [FREE Full text] [doi: 10.1007/s10555-010-9248-x] [Medline: 20830503]

11. Orlando L, Fedele P, Cinefra M, Sponziello F, Calvani N, Chetrì MC, et al. Adjuvant endocrine treatment in premenopausal early breast cancer. Oncology 2009;77 Suppl 1:9-13. [doi: 10.1159/000258490] [Medline: 20130426]

12. Abe O, Abe R, Enomoto K, Kikuchi K, Koyama H, Nomura Y. Tamoxifen for early breast cancer: an overview of the randomised trials. Lancet 1998 May 16;351(9114):1451-1467. [Medline: 9605801]

13. Burstein HJ, Temin S, Anderson H, Buchholz TA, Davidson NE, Gelmon KE, et al. Adjuvant endocrine therapy for women with hormone receptor-positive breast cancer: American Society of Clinical Oncology clinical practice guideline focused update. J Clin Oncol 2014 Jul 20;32(21):2255-2269 [FREE Full text] [doi: 10.1200/JCO.2013.54.2258] [Medline: 24868023]

14. Forbes JF, Cuzick J, Buzdar A, Howell A, Tobias JS, Baum M. Effect of anastrozole and tamoxifen as adjuvant treatment for early-stage breast cancer: 100-month analysis of the ATAC trial. Lancet Oncol 2008 Jan;9(1):45-53. [doi: 10.1016/S1470-2045(07)70385-6] [Medline: 18083636]

15. Baum M, Buzdar A, Cuzick J, Forbes J, Houghton J, Howell A, et al. Anastrozole alone or in combination with tamoxifen versus tamoxifen alone for adjuvant treatment of postmenopausal women with early-stage breast cancer: results of the ATAC (Arimidex, Tamoxifen Alone or in Combination) trial efficacy and safety update analyses. Cancer 2003 Nov 1;98(9):1802-1810 [FREE Full text] [doi: 10.1002/cncr.11745] [Medline: 14584060]

16. Cuzick J, Sestak I, Baum M, Buzdar A, Howell A, Dowsett M, et al. Effect of anastrozole and tamoxifen as adjuvant treatment for early-stage breast cancer: 10-year analysis of the ATAC trial. Lancet Oncol 2010 Dec;11(12):1135-1141. [doi: 10.1016/S1470-2045(10)70257-6] [Medline: 21087898]

17. Winer EP, Hudis C, Burstein HJ, Wolff AC, Pritchard KI, Ingle JN, et al. American Society of Clinical Oncology technology assessment on the use of aromatase inhibitors as adjuvant therapy for postmenopausal women with hormone receptor-positive 
breast cancer: status report 2004. J Clin Oncol 2005 Jan 20;23(3):619-629. [doi: 10.1200/JCO.2005.09.121] [Medline: 15545664]

18. Osterberg L, Blaschke T. Adherence to medication. N Engl J Med 2005 Aug 4;353(5):487-497. [doi: 10.1056/NEJMra050100] [Medline: 16079372]

19. Haynes RB, McDonald HP, Garg AX. Helping patients follow prescribed treatment: clinical applications. JAMA 2002 Dec 11;288(22):2880-2883. [Medline: 12472330]

20. McDonald HP, Garg AX, Haynes RB. Interventions to enhance patient adherence to medication prescriptions: scientific review. JAMA 2002 Dec 11;288(22):2868-2879. [Medline: 12472329]

21. Partridge AH, Avorn J, Wang PS, Winer EP. Adherence to therapy with oral antineoplastic agents. J Natl Cancer Inst 2002 May 1;94(9):652-661 [FREE Full text] [Medline: 11983753]

22. Simpson SH, Eurich DT, Majumdar SR, Padwal RS, Tsuyuki RT, Varney J, et al. A meta-analysis of the association between adherence to drug therapy and mortality. Brit Med J 2006 Jul 1;333(7557):15 [FREE Full text] [doi: 10.1136/bmj.38875.675486.55] [Medline: 16790458]

23. Burkhart PV, Sabaté E. Adherence to long-term therapies: evidence for action. J Nurs Scholarsh 2003;35(3):207. [Medline: 14562485]

24. Partridge AH, LaFountain A, Mayer E, Taylor BS, Winer E, Asnis-Alibozek A. Adherence to initial adjuvant anastrozole therapy among women with early-stage breast cancer. J Clin Oncol 2008 Feb 1;26(4):556-562 [FREE Full text] [doi: 10.1200/JCO.2007.11.5451] [Medline: 18180462]

25. Murri R, Ammassari A, Trotta MP, De LA, Melzi S, Minardi C, et al. Patient-reported and physician-estimated adherence to HAART: social and clinic center-related factors are associated with discordance. J Gen Intern Med 2004 Nov;19(11):1104-1110 [FREE Full text] [doi: 10.1111/j.1525-1497.2004.30248.x] [Medline: 15566439 ]

26. McDonnell PJ, Jacobs MR. Hospital admissions resulting from preventable adverse drug reactions. Ann Pharmacother 2002 Sep;36(9):1331-1336. [Medline: 12196047]

27. Schiff GD, Fung S, Speroff T, McNutt RA. Decompensated heart failure: symptoms, patterns of onset, and contributing factors. Am J Med 2003 Jun 1;114(8):625-630. [Medline: 12798449]

28. Rodgers PT, Ruffin DM. Medication nonadherence: Part II-A pilot study in patients with congestive heart failure. Manag Care Interface 1998 Sep;11(9):67-69. [Medline: 10187590]

29. Rodgers PT, Ruffin DM. Medication nonadherence-Part I: The health and humanistic consequences. Manag Care Interface 1998 Aug;11(8):58-60. [Medline: 10182240]

30. Rasmussen JN, Chong A, Alter DA. Relationship between adherence to evidence-based pharmacotherapy and long-term mortality after acute myocardial infarction. JAMA 2007 Jan 10;297(2):177-186. [doi: 10.1001/jama.297.2.177] [Medline: 17213401]

31. Hughes DA, Bagust A, Haycox A, Walley T. The impact of non-compliance on the cost-effectiveness of pharmaceuticals: a review of the literature. Health Econ 2001 Oct;10(7):601-615. [Medline: 11747044]

32. Fink AK, Gurwitz J, Rakowski W, Guadagnoli E, Silliman RA. Patient beliefs and tamoxifen discontinuance in older women with estrogen receptor-positive breast cancer. J Clin Oncol 2004 Aug 15;22(16):3309-3315 [FREE Full text] [doi: 10.1200/JCO.2004.11.064] [Medline: 15310774 ]

33. Demissie S, Silliman RA, Lash TL. Adjuvant tamoxifen: predictors of use, side effects, and discontinuation in older women. J Clin Oncol 2001 Jan 15;19(2):322-328. [Medline: 11208822]

34. Partridge AH, Wang PS, Winer EP, Avorn J. Nonadherence to adjuvant tamoxifen therapy in women with primary breast cancer. J Clin Oncol 2003 Feb 15;21(4):602-606. [Medline: 12586795]

35. Leventhal H, Nerenz DR, Leventhal EA, Love RR, Bendena LM. The behavioral dynamics of clinical trials. Prev Med 1991 Jan;20(1):132-146. [Medline: 2008422]

36. Goodwin JS, Hunt WC, Humble CG, Key CR, Samet JM. Cancer treatment protocols. Who gets chosen? Arch Intern Med 1988 Oct;148(10):2258-2260. [Medline: 3178383]

37. Kemeny MM, Peterson BL, Kornblith AB, Muss HB, Wheeler J, Levine E, et al. Barriers to clinical trial participation by older women with breast cancer. J Clin Oncol 2003 Jun 15;21(12):2268-2275. [doi: 10.1200/JCO.2003.09.124] [Medline: 12805325]

38. Townsley CA, Selby R, Siu LL. Systematic review of barriers to the recruitment of older patients with cancer onto clinical trials. J Clin Oncol 2005 May 1;23(13):3112-3124. [doi: 10.1200/JCO.2005.00.141] [Medline: 15860871]

39. Kahn KL, Schneider EC, Malin JL, Adams JL, Epstein AM. Patient-centered experiences in breast cancer: predicting long-term adherence to tamoxifen use. Med Care 2007 May;45(5):431-439. [doi: 10.1097/01.mlr.0000257193.10760.7f] [Medline: 17446829$]$

40. Thomas GA, Leonard RC. How age affects the biology of breast cancer. Clin Oncol (R Coll Radiol) 2009 Mar;21(2):81-85. [doi: 10.1016/j.clon.2008.11.006] [Medline: 19071000]

41. Clark GM, Osborne CK, McGuire WL. Correlations between estrogen receptor, progesterone receptor, and patient characteristics in human breast cancer. J Clin Oncol 1984 Oct;2(10):1102-1109. [Medline: 6491696]

42. Diab SG, Elledge RM, Clark GM. Tumor characteristics and clinical outcome of elderly women with breast cancer. J Natl Cancer Inst 2000 Apr 5;92(7):550-556 [FREE Full text] [Medline: 10749910] 
43. Daidone MG, Coradini D, Martelli G, Veneroni S. Primary breast cancer in elderly women: biological profile and relation with clinical outcome. Crit Rev Oncol Hematol 2003 Mar;45(3):313-325. [Medline: 12633842]

44. Quong J, Eppenberger-Castori S, Moore D, Scott GK, Birrer MJ, Kueng W, et al. Age-dependent changes in breast cancer hormone receptors and oxidant stress markers. Breast Cancer Res Treat 2002 Dec;76(3):221-236. [Medline: 12462383]

45. Crivellari D, Aapro M, Leonard R, von Minckwitz G, Brain E, Goldhirsch A, et al. Breast cancer in the elderly. J Clin Oncol 2007 May 10;25(14):1882-1890. [doi: 10.1200/JCO.2006.10.2079] [Medline: 17488987]

46. Aapro MS. Challenges in clinical patient management. Cancer Invest 2010;28 Suppl 1:14-27. [doi: 10.3109/07357907.2010.501648] [Medline: 20653404]

47. Rossi A, Colantuoni G, Maione P, Ferrara C, Airoma G, Barzelloni ML, et al. Chemotherapy of breast cancer in the elderly. Curr Med Chem 2005;12(3):297-310. [Medline: 15723620]

48. Fyles AW, McCready DR, Manchul LA, Trudeau ME, Merante P, Pintilie M, et al. Tamoxifen with or without breast irradiation in women 50 years of age or older with early breast cancer. N Engl J Med 2004 Sep 2;351(10):963-970. [doi: 10.1056/NEJMoa040595] [Medline: 15342804]

49. Hughes KS, Schnaper LA, Berry D, Cirrincione C, McCormick B, Shank B, Radiation Therapy Oncology Group, Eastern Cooperative Oncology Group. Lumpectomy plus tamoxifen with or without irradiation in women 70 years of age or older with early breast cancer. N Engl J Med 2004 Sep 2;351(10):971-977. [doi: 10.1056/NEJMoa040587] [Medline: 15342805]

50. Crivellari D, Price K, Gelber RD, Castiglione-Gertsch M, Rudenstam C, Lindtner J, International Breast Cancer Study Group. Adjuvant endocrine therapy compared with no systemic therapy for elderly women with early breast cancer: 21-year results of International Breast Cancer Study Group Trial IV. J Clin Oncol 2003 Dec 15;21(24):4517-4523. [doi: 10.1200/JCO.2003.03.559] [Medline: 14673038 ]

51. Wildiers H, Kunkler I, Biganzoli L, Fracheboud J, Vlastos G, Bernard-Marty C, International Society of Geriatric Oncology. Management of breast cancer in elderly individuals: recommendations of the International Society of Geriatric Oncology. Lancet Oncol 2007 Dec;8(12):1101-1115. [doi: 10.1016/S1470-2045(07)70378-9] [Medline: 18054880]

52. Canadian Cancer Society's Advisory Committee on Cancer Statistics. Canadian cancer statistics 2013.. 2015. URL: https:/ /www.cancer.ca/ /media/cancer.ca/CW/cancer\%20information/cancer\%20101/Canadian\%20cancer\%20statistics/ canadian-cancer-statistics-2013-EN.pdf [accessed 2015-12-21] [WebCite Cache ID 6dwh6qKys]

53. Edge SB, Cookfair DL, Watroba N. The role of the surgeon in quality cancer care. Curr Probl Surg 2003 Sep;40(9):511-590. [doi: 10.1016/S0011-3840(03)00051-0] [Medline: 12942052]

54. Waterhouse DM, Calzone KA, Mele C, Brenner DE. Adherence to oral tamoxifen: a comparison of patient self-report, pill counts, and microelectronic monitoring. J Clin Oncol 1993 Jun;11(6):1189-1197. [Medline: $\underline{8501505]}$

55. Lebovits AH, Strain JJ, Schleifer SJ, Tanaka JS, Bhardwaj S, Messe MR. Patient noncompliance with self-administered chemotherapy. Cancer 1990 Jan 1;65(1):17-22 [FREE Full text] [Medline: 2293862]

56. Levine AM, Richardson JL, Marks G, Chan K, Graham J, Selser JN, et al. Compliance with oral drug therapy in patients with hematologic malignancy. J Clin Oncol 1987 Sep;5(9):1469-1476. [Medline: 3625261]

57. Cramer JA, Mattson RH, Prevey ML, Scheyer RD, Ouellette VL. How often is medication taken as prescribed? A novel assessment technique. JAMA 1989 Jun 9;261(22):3273-3277. [Medline: 2716163]

58. Gandhi TK, Weingart SN, Borus J, Seger AC, Peterson J, Burdick E, et al. Adverse drug events in ambulatory care. N Engl J Med 2003 Apr 17;348(16):1556-1564. [doi: 10.1056/NEJMsa020703] [Medline: 12700376]

59. Martin RM, Kerry SM, Hilton SR. Initial treatment choices, second-line therapy, and reasons for stopping medication in the treatment of hypertension by general practitioners in England, Scotland and Wales: 1990-1995. Pharmacoepidemiol Drug Saf 1997 Jul;6(4):253-261. [doi: 10.1002/(SICI)1099-1557(199707)6:4<253::AID-PDS284>3.0.CO;2-5] [Medline: 15073776]

60. Eichler GS, Cochin E, Han J, Hu S, Vaughan TE, Wicks P, et al. Exploring concordance of patient-reported information on PatientsLikeMe and medical claims data at the patient level. J Med Internet Res 2016;18(5):e110 [FREE Full text] [doi: 10.2196/jmir.5130] [Medline: 27174602]

61. Meguerditchian A, Stewart A, Watroba N, Roistacher J, Cropp M, Ko C. Application of quality indicators in breast cancer care using linked national registry and administrative claims data. Presented at: 43rd Annual Meeting, American Society of Clinical Oncology; 2007; Chicago, IL.

62. Sclar DA, Chin A, Skaer TL, Okamoto MP, Nakahiro RK, Gill MA. Effect of health education in promoting prescription refill compliance among patients with hypertension. Clin Ther 1991;13(4):489-495. [Medline: 1934001]

63. Hershman DL, Shao T, Kushi LH, Buono D, Tsai WY, Fehrenbacher L, et al. Early discontinuation and non-adherence to adjuvant hormonal therapy are associated with increased mortality in women with breast cancer. Breast Cancer Res Treat 2011 Apr;126(2):529-537 [FREE Full text] [doi: 10.1007/s10549-010-1132-4] [Medline: 20803066]

64. Hess LM, Raebel MA, Conner DA, Malone DC. Measurement of adherence in pharmacy administrative databases: a proposal for standard definitions and preferred measures. Ann Pharmacother 2006;40(7-8):1280-1288. [doi: 10.1345/aph.1H018] [Medline: 16868217]

65. Sikka R, Xia F, Aubert RE. Estimating medication persistency using administrative claims data. Am J Manag Care 2005 Jul;11(7):449-457 [FREE Full text] [Medline: 16044982] 
66. Steiner JF, Prochazka AV. The assessment of refill compliance using pharmacy records: methods, validity, and applications. J Clin Epidemiol 1997 Jan;50(1):105-116. [Medline: 9048695]

67. Trabulsi N, Riedel K, Winslade N, Gregoire J, Meterissian S, Abrahamovicz M, et al. Adherence to anti-estrogen therapy in seniors with breast cancer: how well are we doing? Breast J 2014;20(6):632-638. [doi: 10.1111/tbj.12328] [Medline: 25251847]

68. Krotneva S, Reidel K, Nassif M, Trabulsi N, Mayo N, Tamblyn R, et al. Rates and predictors of consideration for adjuvant radiotherapy among high-risk breast cancer patients: a cohort study. Breast Cancer Res Treat 2013 Jul;140(2):397-405 [FREE Full text] [doi: 10.1007/s10549-013-2636-5] [Medline: 23881523]

69. Krotneva SP, Ramjuan A, Reidel KE, Eguake T, Trabulsi N, Mayo N. Use of hormonal therapy in senior breast cancer patients treated with or without radiotherapy. Curr Oncol 2014;21:e105-e115. [doi: 10.1111/tbj.12328] [Medline: PMC3921034]

70. Ernster VL, Barclay J, Kerlikowske K, Grady D, Henderson C. Incidence of and treatment for ductal carcinoma in situ of the breast. JAMA 1996 Mar 27;275(12):913-918. [Medline: 8598618]

71. Tamblyn R, Huang A, Taylor L, Kawasumi Y, Bartlett G, Grad R, et al. A randomized trial of the effectiveness of on-demand versus computer-triggered drug decision support in primary care. J Am Med Inform Assoc 2008;15(4):430-438 [FREE Full text] [doi: 10.1197/jamia.M2606] [Medline: 18436904]

72. Tamblyn R, Huang A, Kawasumi Y, Bartlett G, Grad R, Jacques A, et al. The development and evaluation of an integrated electronic prescribing and drug management system for primary care. J Am Med Inform Assoc 2006;13(2):148-159 [FREE Full text] [doi: 10.1197/jamia.M1887] [Medline: 16357357]

73. Tamblyn R, Reidel K, Huang A, Taylor L, Winslade N, Bartlett G, et al. Increasing the detection and response to adherence problems with cardiovascular medication in primary care through computerized drug management systems: a randomized controlled trial. Med Decis Making 2010;30(2):176-188. [doi: 10.1177/0272989X09342752] [Medline: 19675319]

74. Buckeridge D, Huang A, Hanley J, Kelome A, Reidel K, Verma A, et al. Risk of injury associated with opioid use in older adults. J Am Geriatr Soc 2010 Sep;58(9):1664-1670. [doi: 10.1111/j.1532-5415.2010.03015.x] [Medline: 20863326]

75. Tamblyn R, Eguale T, Buckeridge DL, Huang A, Hanley J, Reidel K, et al. The effectiveness of a new generation of computerized drug alerts in reducing the risk of injury from drug side effects: a cluster randomized trial. J Am Med Inform Assoc 2012;19(4):635-643 [FREE Full text] [doi: 10.1136/amiajnl-2011-000609] [Medline: 22246963]

76. Bosworth HB, Zullig LL, Mendys P, Ho M, Trygstad T, Granger C, et al. Health information technology: meaningful use and next steps to improving electronic facilitation of medication adherence. JMIR Med Inform 2016;4(1):e9 [FREE Full text] [doi: 10.2196/medinform.4326] [Medline: 26980270]

77. Fraccaro P, Arguello CM, Ainsworth J, Buchan I. Adoption of clinical decision support in multimorbidity: a systematic review. JMIR Med Inform 2015 Jan;3(1):e4 [FREE Full text] [doi: 10.2196/medinform.3503] [Medline: 25785897]

78. Verbrugghe M, Verhaeghe S, Lauwaert K, Beeckman D, Van Hecke A. Determinants and associated factors influencing medication adherence and persistence to oral anticancer drugs: a systematic review. Cancer Treat Rev 2013 Oct;39(6):610-621. [doi: 10.1016/j.ctrv.2012.12.014] [Medline: 23428230]

79. Rossy Cancer Network. URL: https://www.mcgill.ca/rcr-rcn/rossy-cancer-network [accessed 2016-10-04] [WebCite Cache ID 610zTSvcS]

80. Hertzog MA. Considerations in determining sample size for pilot studies. Res Nurs Health 2008 Apr;31(2):180-191. [doi: 10.1002/nur.20247] [Medline: 18183564]

81. Chan YH. Randomised controlled trials (RCTs)-sample size: the magic number? Singapore Med J 2003 Apr;44(4):172-174. [Medline: 12952027]

82. RAMQ. Statistiques annuelles, 2013. URL: https://www.prod.ramq.gouv.qc.ca/IST/CD/CDF DifsnInfoStats/ CDF1_CnsulInfoStatsCNC_iut/RappPDF.aspx?TypeImpression=pdf\&NomPdf=CDB1R01A_PA01_2013_0_O.PDF [accessed 2015-12-21] [WebCite Cache ID 6dwVlExHL]

83. Institut de la statistique Québec. Population du Québec 1971-2014. 2015 Dec 21. URL: http://www.stat.gouv.qc.ca/ statistiques/population-demographie/structure/qc_1971-20xx.htm [accessed 2015-12-21] [WebCite Cache ID 6dwW2L9ID]

84. Tamblyn R, Reid T, Mayo N, McLeod P, Churchill-Smith M. Using medical services claims to assess injuries in the elderly: sensitivity of diagnostic and procedure codes for injury ascertainment. J Clin Epidemiol 2000 Feb;53(2):183-194. [Medline: 10729691]

85. Tamblyn R, Lavoie G, Petrella L, Monette J. The use of prescription claims databases in pharmacoepidemiological research: the accuracy and comprehensiveness of the prescription claims database in Quebec. J Clin Epidemiol 1995

Aug;48(8):999-1009. [Medline: 7775999]

\section{Abbreviations}

AET: adjuvant endocrine therapy

ICD-9: International Classification of Diseases, Ninth Revision

MPR: medication possession ratio

MOXXI: Medical Office of the XXIst Century 
RAMQ: Régie de l'Assurance Maladie du Québec

RAMQ-MD: RAMQ medical service claims database

RAMQ-Rx: RAMQ prescription claims database

RVH: Royal Victoria Hospital

SMH: St. Mary's Hospital

Edited by G Eysenbach; submitted 19.08.16; peer-reviewed by K Crew, J Hensel; comments to author 07.09.16; revised version received 20.09.16; accepted 20.09.16; published 07.11.16

Please cite as:

Meguerditchian A, Tamblyn R, Meterissian S, Law S, Prchal J, Winslade N, Stern D

Adjuvant Endocrine Therapy in Breast Cancer: A Novel e-Health Approach in Optimizing Treatment for Seniors (OPTIMUM): A

Two-Group Controlled Comparison Pilot Study

JMIR Res Protoc 2016;5(4):e199

URL: http://www.researchprotocols.org/2016/4/e199/

doi: $10.2196 /$ resprot.6519

PMID: 27821385

(C)Ari Meguerditchian, Robyn Tamblyn, Sarkis Meterissian, Susan Law, Jaroslav Prchal, Nancy Winslade, Donna Stern. Originally published in JMIR Research Protocols (http://www.researchprotocols.org), 07.11.2016. This is an open-access article distributed under the terms of the Creative Commons Attribution License (http://creativecommons.org/licenses/by/2.0/), which permits unrestricted use, distribution, and reproduction in any medium, provided the original work, first published in JMIR Research Protocols, is properly cited. The complete bibliographic information, a link to the original publication on http://www.researchprotocols.org, as well as this copyright and license information must be included. 